Paideusis

\title{
On the Lived-Experience and Dynamics of Health and Illness: Phenomenological Complexity and Learning Organizations
}

\section{Darren Stanley}

Volume 16, Number 3, 2007

URI: https://id.erudit.org/iderudit/1072489ar

DOI: https://doi.org/10.7202/1072489ar

See table of contents

Publisher(s)

Canadian Philosophy of Education Society

ISSN

0838-4517 (print)

1916-0348 (digital)

Explore this journal

Cite this article

Stanley, D. (2007). On the Lived-Experience and Dynamics of Health and Illness: Phenomenological Complexity and Learning Organizations. Paideusis, 16(3), 57-68. https://doi.org/10.7202/1072489ar
Article abstract

Many contemporary theories of "complex" dynamical phenomena have been used to explain and understand a wide range of matters pertaining to the health of learning organizations; however, a more sensitive approach is required which also takes into account the lived-experience of health where the experiencing subject is also a part of an epistemological framework which Letiche1 describes as "phenomenal complexity theory." To be sure, there is a need for a complexity-related framework which also studies human consciousness by attending to the structures of lived-experience-in the case of this paper, the lived-structures of health. To this end, this paper examines: the notion of "health" through a circulation of lived-experience; the concept of dynamical systems in an emerging framework for studying healthy learning organizations.
This document is protected by copyright law. Use of the services of Erudit (including reproduction) is subject to its terms and conditions, which can be viewed online.

https://apropos.erudit.org/en/users/policy-on-use/ 


\title{
On the Lived-Experience and Dynamics of Health and Illness: Phenomenological Complexity and Learning Organizations
}

\author{
DARREN STANLEY \\ University of Windsor, Windsor, Canada
}

\begin{abstract}
Many contemporary theories of "complex" dynamical phenomena have been used to explain and understand a wide range of matters pertaining to the health of learning organizations; however, a more sensitive approach is required which also takes into account the lived-experience of bealth where the experiencing subject is also a part of an epistemological framework which Letiche ${ }^{1}$ describes as "phenomenal complexity theory." To be sure, there is a need for a complexity-related framework which also studies human consciousness by attending to the structures of lived-experience-in the case of this paper, the lived-structures of health. To this end, this paper examines: the notion of "bealth" through a circulation of lived-experience; the concept of dynamical systems in an emerging framework for studying bealtby learning organizations.
\end{abstract}

\section{Complexity and Lived-Experience: Common Ground to Be $\mathrm{Had}$}

A genuine reconciliation of first- and third-person methodologies asks us to discover ... conceptual complementarities and to trace out in detail their common ground. It does not require bridge-building because the bridge is already there. ${ }^{2}$

To be sure, where many complexity-related theories, as a hermeneutic, continue to be imposed upon different health-related phenomena to explain and categorize such concerns, a more sensitive approach to understanding various health matters is required where the common ground of complexity science and lived-experience might gesture towards a shared set of patterns; principles; and insights into, and across, multiple scales of organization. That is, there is a need to include the experiencing subject as part of the epistemological basis, which Letiche ${ }^{3}$ describes as "phenomenal complexity theory," to frame a study of human and organizational health—one that is also attentive to the lived-structures of

\footnotetext{
${ }^{1}$ Hugo Letiche, "Phenomenal Complexity Theory as Informed by Bergson," Journal of Organizational Change Management 13, no. 6 (2000).

${ }^{2}$ Maxine Sheets-Johnstone, "Preserving Integrity against Colonization," in Perils and Promises of Interdisciplinary Research (University of Copenhagen: 2002). quoted in J. A. Scott Kelso and David A. Engstrøm, The Complementary Nature (Cambridge, MA: MIT Press, 2006), p. 236.

${ }^{3}$ Letiche, "Phenomenal Complexity Theory as Informed by Bergson."

(C) Copyright 2007. The author, Darren Stanley, assigns to Paideusis the right of first publication and educational and non-profit institutions a non-exclusive license to use this document for personal use and in courses of instruction provided that the article is used in full and this copyright statement is reproduced. Any other usage is probibited without the express permission of the author.
} 
meaning as they manifest through the fundamental thematic existentials of spatiality, corporality, temporality, and relationality. ${ }^{4} \mathrm{~A}$ central purpose for this paper, therefore, is to consider the possibility of a human science that speaks to, and with, complexity science. More specifically, this paper proposes to examine the notion of "health" in light of lived-experiences of wellness and illness and of the concept of dynamical systems in the context of healthy learning organizations. This call for a greater consideration to be given to the "overlap" in matters scientific and phenomenological is not new. What is potentially new, however, is a call for complexity scholars, in particular, and phenomenologists to engage in shared work together. Even more, there is a need for collaboration in this area which might shed some further light on a wide range of educational matters.

The words that mark the beginning of this section, by phenomenologist Maxine SheetsJohnstone, resonate to some degree with similar views expressed by Varela, ${ }^{5}$ by Varela and Shear, ${ }^{6}$ and by Roy, Petitot, Pachoud, and Varela, ${ }^{7}$ who point to the need to "move beyond the gap" or to "build the appropriate links" in a "necessary circulation" between first-person accounts and third-person descriptions of natural phenomena. This apparent duality between the inside ("first-person accounts") and the outside ("third-person descriptions"), however, has produced a "misleading divide."8 As Sheets-Johnstone suggests, there is no divide to speak of as "the bridge is already there." That is, as Varela and Shear propose, "phenomenal data can provide the common first-person/third-person ground" for particular kinds of questions raised in the natural and social sciences. As such, we find data and ideas that are shared and distributed across several discourses in a transdisciplinary manner-not translated from one discourse to another.

To argue otherwise sets up a dualistic conceptualization of "consciousness" and "life"- the immaterialism of the mind and the exteriority of the world. ${ }^{9}$ Some philosophers of mind do not find this troubling; however, they do invoke what is commonly referred to as "the hard problem of consciousness." 10 In other words, such a framework brings into play a radical discontinuity between the mind and life. As Thompson suggests, such a division can only be met with some suspicion ${ }^{11}$ — this is a shared sentiment. As Thompson writes:

Contrary to both dualism and materialism, life or living being is already beyond the gap between "internal" and "external." A purely external or outside view of structure and function is inadequate for life. A living being is not sheer exteriority (partes extra partes) but instead embodies a kind of interiority, that of its own immanent purposiveness. This interiority, as we

\footnotetext{
${ }^{4}$ Max van Manen, Researching Lived Experience: Human Science for an Action Sensitive Pedagogy (Albany, NY: State University of New York Press, 1990).

${ }^{5}$ Francisco J. Varela, "The Specious Present: A Neurophenomenology of Time Consciousness," in Naturalizing Phenomenology: Issues in Contemporary Phenomenology and Cognitive Science, Ed. Jean Petitot, et al. (Standford, CA: Standford University Press, 1999).

${ }^{6}$ Francisco J. Varela and Jonathan Shear, "First-Person Methodologies: What, Why, How?," in The View from Within: First-Person Approaches to the Study of Consciousness, Ed. Francisco J. Varela and Jonathan Shear (Bowling Green, OH: Imprint Academic, 2000).

${ }^{7}$ Jean-Michel Roy et al., "Beyond the Gap: An Introduction to Naturalizing Phenomenology," in Naturalizing Phenomenology: Issues in Contemporary Phenomenology and Cognitive Science, Ed. Jean Petitot, et al. (Stanford, CA: Stanford University Press, 1999).

${ }^{8}$ Varela and Shear, "First-Person Methodologies: What, Why, How?"

${ }^{9}$ Evan Thompson, Mind in Life: Biology, Phenomenology, and the Sciences of Mind (Cambridge, MA: Harvard University Press, 2007), p. 225.

${ }^{10}$ This tension concerning objective and subjective perspectives continues to be debated to this day. Thomas Nagel, who stated that "Consciousness is what makes the mind-body problem really intractable," offers an early discussion on this matter. Cf., Thomas Nagel, "What Is It Like to Be a Bat?" Philosophical Review 83 (1974).

${ }^{11}$ Ibid.: p. 224.
} 
have seen, comprises the self-production of an inside that specifies an outside to which that inside is constitutively and normatively related. ${ }^{12}$

That is, any such separation-as with an apparent separation between the gaze of a researcher and another person's consciousness of lived experience-is troubling and requires some further reconsideration, if not a different tact.

In summary, this paper is intended to be an argument for complexity science researchers to be more attentive to the "ground" of lived-experience where complexity science and phenomenology might be seen as mutually co-specifying sources of analogies and, similarly, that scholars of the mind might give some consideration to matters of science-specifically complexity science. To paraphrase Varela, science ought to pay some attention to life and experience when doing science, and human beings ought to pay some attention to science when living. ${ }^{13}$ Consequently, some consideration could be given to certain complexity-related ideas like self-organization, connectedness, and emergence, etc., to name some concepts which resonate in a complementary fashion with the study of lived-experiences. Complexity science seems to trouble the apparent discontinuities between and across life's seemingly disconnected living phenomena, i.e., organizational phenomena that, while coincidental, are not coimplicated. ${ }^{14}$ Thus, a transdisciplinary approach would be quite useful—certainly beneficial in light of the "hard problem of consciousness" - to understand human experiences of all kinds, but especially matters of health and healthy learning organizations through a shared framework.

\section{Sketching the Common Ground}

There is much in the large body of literature addressing this apparent chasm between objective and subjective reports of reality suggesting that first-person accounts and third-person descriptions of natural phenomena are incommensurable. ${ }^{15}$ There is also another body of work that speaks to the "fundamental complementarity" of these two different research orientations to the world. ${ }^{16}$ In fact, it would seem that historically these two spheres of inquiry have been wrongly pried apart. Rather than attributing either/or thinking to the nature of living phenomena, there is a need to "obscure the inbetween dynamic realities that constitute life itself and in turn how these realities rest on complementary rather than oppositional pairs." 17 It is, as neuroscientist Scott Kelso writes, that the "reconciliation of first-third-person accounts of natural phenomena promises much in helping us to understand ourselves, other creatures, and the world we live in." 18 The implications for learning, as we will see, could be profound.

Many complexity-related theories suggest that they are anti-mechanistic frameworks; however, this notion is not shared by all scholars and researchers in the complexity field. For instance, in their

\footnotetext{
12 Ibid.: p. 224-25.

${ }^{13}$ Gary A. Ratson, The Meaning of Health: The Experience of a Lifetime (Victoria, British Columbia, Canada: Trafford, 2003), p. 18.

${ }^{14}$ Brent Davis, "Complexity and Education: Some Vital Simultaneities" (paper presented at the Third Conference on Complexity Science and Educational Research, Loranger, LO, 2005).

15 Francisco J. Varela and J. Shear, The View from Within: First-Person Approaches to the Study of Consciousness (Exeter, England: Imprint Academic, 1999).

${ }^{16}$ Cf., Francisco J. Varela, Ethical Know-How: Action, Wisdom, and Cognition, Writing Science (Stanford, CA: Stanford University Press, 1999), Francisco J. Varela, Evan Thompson, and Eleanor Rosch, The Embodied Mind: Cognitive Science and Human Experience (Cambridge, MA: The MIT Press, 1991).

${ }^{17}$ Maxine Sheets-Johnstone, Quotation from the back cover of the dust jacket of Kelso and Engstrøm, The Complementary Nature.

18 Ibid., p. 236.
} 
works on "complex responsive processes," Ralph Stacey, ${ }^{19}$ Patricia Shaw, ${ }^{20}$ and Douglas Griffin ${ }^{21}$ critique and challenge what certain conceptual frameworks - such as systems theory-can and cannot do. For example, they point out how the troubling notion of "boundaries" creates a range of epistemological, methodological, and conceptual concerns. That is, a systems perspective continues to cut up the world into bits and pieces. Nevertheless, it does seem that there is a desire for many complexity theorists to see what they do as "putting the world back together"- to tend to all natural phenomena holistically through the relationality of the phenomena.

To be sure, Stacey's work does raise some difficulties with conceptual frameworks of dynamical systems, especially the notion of "boundaries"; this concern will not be taken up here. What is important here, however, is that, as a complexity-related framework, Stacey's work on "complex responsive processes" makes no separation between the individual and the collective. In other words, the individual is social through and through, arising through the same non-linear, interactions of gesture-and-response in the here-and-now: that is, the mind and the world around one's self are coimplicated. As complexity-related concepts, non-linearity and interaction are important here. Moreover, as self-organizing phenomena, the mind and social collectives as social phenomena are emergent, arising through the coherence of locally organized bodies-in-interaction. Similarly, in the same light as Varela's comments on the topic of "emergence," the concept of emergence is the "property of a complex, distributed process mediated by social interactions." 22 Herein, some of the shared ground of complexity science and phenomenology begins to appear.

It has not escaped the attention of some that lived-experience is irreducible. ${ }^{23}$ In other words, phenomenal data cannot be reduced to, or derived from, other data or parts. Similarly, in dynamical systems theories, a wide range of phenomena arise through the local interactions of improvising bodies following certain rules that, through the passage of time and space, give rise to larger on-going dynamic and coherent patterns in a self-organizing fashion. Emergent phenomena defy analysis-a term which inherently suggests a process of undoing something: like one's shoes, perhaps. But, to be sure, any attempt to "undo" some living phenomenon removes or otherwise ignores the relational qualities that "hold" the phenomenon together to begin with. Emergent phenomena transcend the identities of those elements that give rise to a property that cannot be found at the level of the interacting parts.

To be sure, the concept of emergence does not suggest a uni-directional process arising from the "bottom up"-although metaphorically it may. Emergence is best thought of in terms of processes wherein parts and whole co-specify one another. That is, where the parts of the emergent whole and the whole itself may be dependent upon one another, they are not determined as such. A machine, for example, may be entirely determined by its parts; living phenomena, however, are not. Lived experience, like other emergent living phenomena, is manifest in much the same way. As such, any complexity-related perspective should account for, and show some sensitivity to, lived-experience. In the context of health and healthy organizational dynamics, a complexity framework should attend to the lived-experience of health and wellness to identify the presence of such patterns which happen at, and across, all scales of organization. That is, the connectivity of life makes health and illness an emergent phenomenon that touches all scales of living organization. A picture of what this might look like will be examined next.

\footnotetext{
${ }^{19}$ Cf., Ralph D. Stacey, Complex Responsive Processes in Organizations: Learning and Knowledge Creation (New York: Routledge, 2001).

${ }^{20}$ Cf., Patricia Shaw, Changing Conversations in Organizations: A Complexity Approach to Change (New York: Routledge, 2002).

${ }^{21}$ Cf., Douglas Griffin, The Emergence of Leadership : Linking Self-Organization and Ethics, Complexity and Emergence in Organizations (London: Routledge, 2002).

${ }^{22}$ Varela, Ethical Know-How: Action, Wisdom, and Cognition.

${ }^{23}$ Varela and Shear, "First-Person Methodologies: What, Why, How?"
} 


\section{A Picture of Health}

The notion of "health," especially for one attentive to its etymology, is strongly related to the idea of "wholeness." 24 Insofar as this notion of health might apply to the biological being, it must work with other scales of organization as well-that is, the myriad of other nested living bodies of the world: cellular assemblies, physiological subsystems, the biological body, social collectives, governance structures, bodies of local ecologies, and the entire planetary body. It is within and across these many scales of organization that we might find and understand the nature of health's wholeness and its manifestation. Certainly, one's sense of health must include the physiological, psychological, and spiritual, but this sense of health must extend beyond these and into other scales. Life, after all, is "an aggregate of vital phenomena" 25 crucial to the well-being of all creatures great and small.

To the extent that health might concern individuals, families, communities, cultures, and local ecologies, the notion of health as wholeness must include everything. That is, health as a matter of some concern cannot be understood as a property of certain selected scales of organization. The connectedness of every scale makes health a property which is shared across every scale of organization. The western medical profession has a long history of focusing on particular structures that seem to cease or fail to work properly. For example, when someone breaks an arm, a doctor seldom finds much of a reason to treat the whole person. The doctor can just treat the break in the arm. In a manner which could be described as "commodification," the doctor just has to do something to us as if we are a mere machine. As living organizations, we are connected in particular ways that have us connected in an entanglement of cross-scale relationships that holds life together in its infinite nestedness of co-implicated phenomena.

To be sure, a great deal more attention still needs to be given to the lived-experience of illness or disease. Indeed, as Ratson writes, "the meaning of health obliges us to consider our own experience of biological, psychological, and spiritual realities." 26 It is not enough to know the nature of the disease that may have some hold on an individual; one must know the person even more. ${ }^{27}$ Certainly, health is not simply the absence of disease or illness, because healthiness and well-being for a healthy being has a "hidden character" which "does not actually present itself to us." 28 What does and can present itself to us is disease or illness. To paint a picture of health, one also must turn to patterns of disease and illness as they present themselves to us in particular and recognizable ways.

\section{A Phenomenology of Dis-Ease: Complexity and Lived-Experience}

Phenomenology, Merleau-Ponty tells us, is all about "the study of essences." 29 But it is also, he tells us, a "philosophy for which the world is always 'already there' before reflection begins" which "offers an account of space, time and the world as we 'live' them." As such, there is, as van Manen points out, the Husserlian notion of a "returning to the things themselves." 30 In so doing, a renewed contact with original experience is made manifest through various thematic dimensions and modalities. These themes, in the context of this paper, will be examined for their resonance with life-in particular as one might recognize them in experiences of sickness and well-being.

\footnotetext{
${ }^{24}$ Ratson, The Meaning of Health: The Experience of a Lifetime.

${ }^{25}$ W. A. Newman Dorland, Dorland's Medical Dictionary (New York, NY: Saunders Press, 1980).

${ }^{26}$ Ratson, The Meaning of Health: The Experience of a Lifetime, p. 9.

${ }^{27}$ Sir William Osler, MD, quoted in Ibid.

${ }^{28}$ Hans Georg Gadamer, The Enigma of Health: The Art of Healing in a Scientific Age, trans. Jason Gaiger and Nicholas Walker (Stanford, CA: Stanford University Press, 1996), p. 107.

${ }^{29}$ Maurice Merleau-Ponty, Phenomenology of Perception (London: Routledge, 1962), p. vii.

${ }^{30}$ van Manen, Researching Lived Experience: Human Science for an Action Sensitive Pedagogy, 1990, p. 31.
} 
Generally speaking, human beings do not notice their bodies during occasions of common everyday healthfulness. It is, as Sartre describes, the body being "passed over in silence." ${ }^{1}$ In fact, it is "illness and not health which 'objectifies' itself, which confronts us as something opposed to us and which forces itself on us." 32 It is important, therefore, to recognize that in matters of good health that one does not notice the world in the same manner as when one is ill. As van Manen writes:

It is significant that it is much more difficult to describe the experience of health than the experience of illness. People who are trying to study health or well-being rather than illness discover that the elusiveness of the phenomenon of health parallels the elusiveness of the ordinary experiences of the body in its "natural" taken-for-granted or silent modality. As long as we are healthy we may not have reason to take notice of our corporeal being. ${ }^{33}$

On the other hand, for the individual who is sick, directing his or her gaze upon a body that once was previously silent, the body now discloses itself quite differently. Phenomenologist van den Berg describes this change in the bodily relationship where, for the healthy individual, a person is:

allowed to be his body and he makes use of this right eagerly: he is his body. Illness disturbs this assimilation. Man's body becomes foreign to him. An intruder makes it his headquarters and it becomes uninhabitable to the sick person. ... The trusted ally has become an antagonist, a fierce enemy. The sick person has to revolt against it. ${ }^{34}$

In other words, the once previously quiet friend has turned against the ill or diseased individual. And, so, the body enters a different modality: one that reflects an unliveable-even an adversarial—relation. The sick individual has, somehow, lost control. But how might one understand—let alone explain — the nature of this "loss"?

In the enterprise of medical science, there is no denying the success of an approach to understanding the world by tending to an apparently well-ordered and predictable set of linear relationships that have permitted or suggested that human beings could be in control of the world. Of course, non-linearity need not imply that control is not possible. ${ }^{35}$ An inability to predict and control some phenomenon does not imply that it is unintelligible. Indeed, such is the case of many complex emergent phenomena that arise through a collectivity of interactions and relations. To be sure, comprehending emergent phenomena requires an understanding that goes far beyond knowing about the "parts" of a system and their interactions. An emergent phenomenon, in fact, may show itself in different "states" depending upon the nature of the interactions of the parts. The nature of human health is one such phenomenon.

Complexity science suggests that we are thoroughly embedded in the world in a manner that is fundamentally different from previous scientific characterizations framed by notions of predictability and control. Certainly, while complexity science might suggest that little control may be exerted "over" a system, as if any observer might be able to stand "outside" of a given system, the notion of "participating" rather than "controlling" might be more appropriate in terms of understanding how human beings might influence a system. Rather than being a naïve observer standing outside some phenomenon, one might find a better understanding of how the world, of which human beings are

\footnotetext{
31 Jean Paul Sartre, Being and Nothingness: An Essay on Phenomenological Ontology (New York: Philosophical Library, 1956).

32 Gadamer, The Enigma of Health, 1996, p. 107.

${ }_{33}$ Max van Manen, "Modalities of Body Experience in Illness and Health," Qualitative Health Research: An International, Interdisciplinary Journal 8, no. 1 (1998): p. 13.

${ }^{34}$ Jan H. van den Berg, The Psychology of the Sickebed (Buffalo, NY: Prometheus Books, 1967), pp. 66-67.

${ }^{35}$ Ricard V. Solé and Brian C. Goodwin, Signs of Life: How Complexity Pervades Biology (New York: Basic Books, 2000).
} 
always and already a part, might work as it does through the notion of "participation." As Gadamer suggests:

Health is not a condition that one retrospectively feels in oneself. Rather, it is a condition of being involved, of being in the world, of being together with one's fellow human beings, of active and rewarding engagement in one's everyday tasks. ${ }^{36}$

In times of illness, the body - a diseased object—is sometimes said to be encumbered by illness where the body is blocked in, or hampered from, participation in the world. Put differently, particular kinds of "connections" are crucial and vital to healthy, living phenomena. ${ }^{37}$ Human beings cannot selfregulate themselves in isolation from the rest of the world: human beings require contact with other human beings to form relationships. ${ }^{38}$ Connections or relations, in fact, are a matter of survival for human beings and are a part of human evolution. Such a concept, moreover, points to the need for interaction, iterated over time and in space, with one another and ourselves. An individual encumbered by illness remains strongly disconnected from the world in time and space.

For a person who suffers from some kind of illness or injury, there is often the need to be reconnected with, and to, his or her body through a liveable relation. ${ }^{39}$ That is, the relationship with one's body has become "broken, disrupted, or disturbed." 40 For an individual who is ill, the quality of the body's experience can be quite complex and ambiguous. As a guide for reflection on the experience of being ill, corporality (or the lived-body in various modes of well-being and illness) shows itself as an important aspect of the world, since one is always bodily present in the world. Certainly, serious illness changes the way a person experiences the many dimensions of that person's life. Not only does an illness change the complex relations with, and to, one's body, but a serious illness can change the way in which one experiences time, the relation to lived-space, and the lived-relations with others. Just as one discovers a body reflecting upon itself as a body — as an object - the unity of one's entire existence becomes fragmented and broken with, and across, the other lived existentials of time, space, and relations.

Of course, one can never become thoroughly objectified and cut off from the world-not without being dead to the world. Still, this sense of disconnectedness is something which is felt, existentially speaking. As in everyday life where one must be able to forget one's body to be attentive to the things of the world and those projects of involvement, one sometimes "loses track of time." Indeed, this suggests a particular modality of lived-time-for the healthy individual. This kind of temporality is "subjective time as opposed to clock time." 41 Unquestionably, the world was-and perhaps still is-viewed and/or felt as some mechanical timepiece. ${ }^{42}$ Kepler, for instance, spoke of the universe as being "likened not to a divine organism but rather to a clockwork." 43 Such a view of time as absolute, linear and uniform, however, does not reflect all modalities of lived-time-certainly not in the

\footnotetext{
${ }^{36}$ Gadamer, The Enigma of Health, 1996, p. 113.

${ }^{37}$ Darren Stanley, "Comparative Dynamics: Healthy Collectivities and the Pattern Which Connects," Complicity: An International Journal of Complexity and Education 3, no. 1 (2006), Darren Stanley, "On the Importance of Connectivity in Healthy Learning Organizations: A Comparative Dynamics Perspective" (paper presented at the Proceedings of the 2005 Complexity Science and Educational Research Conference, Loranger, LA, November 2022 2005).

${ }^{38}$ Ralph D. Stacey, Complexity and Group Processes: A Radically Social Understanding of Individuals (New York: BrunnerRoutledge, 2003).

${ }^{39}$ van Manen, "Modalities of Body Experience in Illness and Health."

${ }^{40}$ Ibid.

${ }^{41}$ van Manen, Researching Lived Experience: Human Science for an Action Sensitive Pedagogy, 1990.

${ }^{42}$ Jay Griffiths, A Sideways Look at Time (New York: Jeremy P. Tarcher/Putnam, 2002).

${ }^{43}$ Gary Eberle, Sacred Time and the Search for Meaning, 1st Ed. (Boston: Shambhala Publications, 2003), p. 116.
} 
everyday sense of time for a healthy human being. This inherited account of time from a clockwork universe in contemporary Western culture is rather insufficient.

Prior to the notion of a clockwork universe, an invention of the Age of Reason, time was thought to be, and to be experienced as, fluid and variable: Its qualitative nature became more homogenous, regular and linear. Lived-time, however, presents itself as having "a complex texture (evidence that we are not dealing with a 'knife-edge' present), a texture that dominates our existence to an important degree." 44 Lived-time is an organized dynamic structure, where "now" lies in the "center" of, and is bounded by, a moveable horizon where the structure moments of past, present, and future form an original synthesis. ${ }^{45}$ To be sure, "our time sense thoroughly pervades our experience of what it means to be human." 46

This sense of time, of being in touch with the natural rhythms of the cosmos, is felt less and less for many people as they are becoming more and more out of sync with the world. In other words, a kind of disconnection has occurred and still is occurring, making time appear flat, rushed, inflexible and almost assembly-line in its tempo. As such, any sense of personal "nowness" no longer exists given the need to make it fit in with the persistent and precise ticking of the minute hand of a clock, the uniform blocks of time in one's daily agenda, and the linear sequence of days on a calendar. Our collective wellbeing has become compromised: A chronic health issue is manifesting itself, expressed through a particular sense of lived-time.

If one should adhere to the notion that lived-experience is an emergent phenomenon, then time, as some existential dimension of the life-world, must likewise emerge from localized interactions-inthe-world. Depending upon the nature of the interactions, the phenomenon of time could be described in terms of a fractal structure where the "center" of time might vary in terms of its "distance" to the ever-shifting and mobile horizon of one's personal "now." As such, fractal organizations are healthy organizations and vice-versa and a diminished sense of time would correlate to an unhealthy organization. As Ratson writes: "the emergence of both human health and disease is coupled to our perception of time." 47

In addition to this sense of one's own body and felt-time during occasions of illness or injury, a very different relation to others and the space around one's self is likewise often experienced. "The body-self is not a secularized private domain of the individual person but an organic part of a sacred, sociocentric world, a communication system involving exchanges with others (including the divine)." 48 That is, the meaning for one's self in illness likewise points to our relations to, and with, the rest of the world. One's body is not simply one's own, but is also a part of the larger world. When I grow depressed during the short winter months and precious little sunlight has appeared, I find myself disconnecting and disconnected from my friends and peers. And, when it has gotten particularly bad, I find myself sleeping more often in my bed - a bed which takes on a very different feel from the bed where I would "normally" sleep in when I am well. This special relationship that a person has with his or her bed in times of illness is spoken of by van den Berg all too well, and it is something that I can recognize in my own times of dis-ease. ${ }^{49}$ While I may certainly recognize the world as it continues outside my window, it goes on without me, and I feel quite disconnected from it.

\footnotetext{
44 Varela, "The Specious Present: A Neurophenomenology of Time Consciousness," p. 268.

45 Sartre, Being and Nothingness: An Essay on Phenomenological Ontology, p. 83, Varela, "The Specious Present: A Neurophenomenology of Time Consciousness."

${ }^{46}$ Eberle, Sacred Time and the Search for Meaning, p. 60.

${ }^{47}$ Larry Dossey, Space, Time, and Medicine (Boston: Shambhala Publications, 1982), p. 21.

48 Arthur Kleinman, The Illness Narratives: Suffering, Healing and the Human Condition. (New York: Basic Books, 1988), p. 11 .

${ }^{49}$ van den Berg, The Psychology of the Sickbed, 1967.
} 
At the heart of this constructed picture of health and the shared ground of complexity and livedexperience is the notion that connections are crucial to life and its attending vital signs. ${ }^{50}$ The importance of connections is important to orient ourselves a bit differently to the world and its many dimensions and aspects as a dynamical system as framed by the notion of health. All in all, a different kind of picture of the world, one more (w)holistic framed, is needed.

\section{A Picture of Healthy Learning Organizations}

When it comes down to it, human beings are more or less "whole." The notion, however, that disease begins and ends with the body, as if it were a machine, has proven inadequate. Clearly, a better picture of health is needed-one framed by a different metaphor might prove more useful, if not simply helpful, to understand the vitality of complex dynamical phenomena. Moreover, that picture must include, and be attentive to, lived-experience.

There is compelling evidence that there is a conceptual crisis-something that Capra has described as a "crisis of perception" 51 _ facing society, the education system, the medical community, economics, the environment, etc. Part of this crisis could be addressed through a greater attentiveness to the study and understanding of complex dynamical systems and the self-organizing nature of emergent phenomena. ${ }^{22}$ Moreover, this crisis of perception that society faces could be helped by paying closer attention to our lived-experience. As such, by tending to the common ground of lived-experience and complexity, especially in light of a complexified and felt sense of health, society might recover from decades - even centuries - of dis-ease, violence, environmental degradation, and generally a multitude of toxic relationships as opposed to "a web of relationships that include the human observer and his or her consciousness in an essential way." 53

How, then, has this conceptual crisis affected the education system and the project of schooling? That is, in light of the discussion within this paper, one might also ask, "How is such a system connected as a phenomenon which could be described as healthy or diseased?" The education system, to be sure, is a thoroughly embedded organization, one which includes other smaller organizational bodies and which can be found within other local ecologies. It is connected in various degrees to other forms. As a class of students, a school, a community within a larger neighborhood, a neighborhood in a city, and so on, these various "bodies of knowledge" are already nested and connected in particular ways. Put this way, what kinds of patterns appear when the connectivity within this web of relations shifts and sways in time from a web of minimal connectivity to too much connectivity to being somewhere in between?

To be sure, in the face of illness or disease, one's connectivity with the world shifts away from some "happy median." And, whether there is too little or too much connectivity, our ability to function in a healthy way begins to disappear. For the student who sits in a classroom, connections might appear at many levels: neurologically, biologically, mentally, socially, and culturally. In this situation where a standards-based curriculum might prompt an engagement with culturally irrelevant abstractions without much interaction with other classmates, connections are unlikely. In fact, the meaningfulness of such connections for the student is diminished to some degree. Under such

\footnotetext{
${ }^{50}$ Stanley, "On the Importance of Connectivity in Healthy Learning Organizations: A Comparative Dynamics Perspective".

${ }^{51}$ Fritjof Capra, The Turning Point: Science, Society, and the Rising Culture (Toronto: Bantam Books, 1983).

${ }^{52}$ Darren Stanley, "Creating Healthy Learning Organizations: A Complex Approach to a Crisis of Perception " in Approaches to Educational Leadership and Practice, Ed. William Smale and Kelly Young (Calgary, Alberta, Canada: Detselig Enterprises, To Appear).

${ }^{53}$ Fritjof Capra, "Foreword," in Space, Time and Medicine (Boston: New Science Library, 1982), p. x.
} 
circumstances, we might wonder why such a student might appear distracted, withdrawn, or to be just not "getting" it.

One might think that this classroom is not "working" for the student. To be sure, the student is not some cog in a larger machine which one might call the classroom or the school. One cannot find "replacement parts" to fix the "problem" here. At best, it seems that while, as the teacher, I might attempt to influence or prompt certain insights and ways of thinking in my students, forcing such connections to appear across so many different scales is a grand task. Nevertheless, such connections must be made at, across, and between many different levels. But how can such a thing happen with emergent, self-organizing phenomena? The difficulty lies with the notion that one might stand outside of some system or organization so as to control it. But naturally one cannot.

Whether I may be "the teacher" or "the researcher," I am also and already a co-participant in the world: I am co-implicated in the world-connected with, and to, it at many different "levels." In this web of connections, my own presence and actions-in-the-world can cascade and ripple through a network of connections, returning to myself. In this manner, attempting to "fix" the "problem" of the disengaged student or "improve" one's health cannot be carried out adequately as if it were some linear process. The world is not just connected linearly: the many scales of organization from the neurological, biological, sociological, and cultural levels of life make the connected nature of the world more like a thoroughly entangled web of complex relationships. Clearly you and I must be connected to the world in particular ways, albeit in slightly different ways. So what are we to do? To feel whole-to feel like we are a part of whole-we can only aim to be more connected in healthy ways to enhance our collective healthiness.

\section{References}

Capra, F. "Foreword." In Space, Time and Medicine, vii-xi. Boston: New Science Library, 1982.

Capra, F. The Turning Point: Science, Society, and the Rising Culture. Toronto: Bantam Books, 1983.

Davis, B. "Complexity and Education: Some Vital Simultaneities." Paper presented at the Third Conference on Complexity Science and Educational Research, Loranger, LO 2005.

Dorland, W. A. N. Dorland's Medical Dictionary. New York, NY: Saunders Press, 1980.

Dossey, L. Space, Time, and Medicine. Boston: Shambhala Publications, 1982.

Eberle, G. Sacred Time and the Search for Meaning. 1st ed. Boston: Shambhala Publications, 2003.

Gadamer, H. G. The Enigma of Health: The Art of Healing in a Scientific Age. Translated by Jason Gaiger and N. Walker. Stanford, CA: Stanford University Press, 1996.

Griffin, D. The Emergence of Leadership : Linking Self-Organization and Ethics, Complexity and Emergence in Organizations. London: Routledge, 2002.

Griffiths, J. A Sideways Look at Time. New York: Jeremy P. Tarcher/Putnam, 2002.

Kelso, J. A. S., and D. A. Engstrøm. The Complementary Nature. Cambridge, MA: MIT Press, 2006.

Kleinman, A. The Illness Narratives: Suffering, Healing and the Human Condition. New York: Basic Books, 1988.

Letiche, H. "Phenomenal Complexity Theory as Informed by Bergson." Journal of Organizational Change Management 13, no. 6 (2000): 545-57.

Merleau-Ponty, M. Phenomenology of Perception. London: Routledge, 1962.

Nagel, T. "What Is It Like to Be a Bat?" Philosophical Review 83 (1974): 435-50.

Ratson, G. A. The Meaning of Health: The Experience of a Lifetime. Victoria, British Columbia, Canada: Trafford, 2003.

Roy, J.-M., J. Petitot, B. Pachoud, and F. J. Varela. "Beyond the Gap: An Introduction to Naturalizing Phenomenology." In Naturalizing Phenomenology: Issues in Contemporary Phenomenology and Cognitive Science, Edited by J. Petitot, F. J. Varela, B. Pachoud and J.-M. Roy, 1-80. Stanford, CA: Stanford University Press, 1999. 
Sartre, J. P. Being and Nothingness: An Essay on Phenomenological Ontology. New York: Philosophical Library, 1956.

Shaw, P. Changing Conversations in Organizations: A Complexity Approach to Change. New York: Routledge, 2002.

Sheets-Johnstone, M. "Preserving Integrity against Colonization." In Perils and Promises of Interdisciplinary Research. University of Copenhagen, 2002.

Solé, R. V., and B. C. Goodwin. Signs of Life: How Complexity Pervades Biology. New York: Basic Books, 2000.

Stacey, R. D. Complex Responsive Processes in Organizations: Learning and Knowledge Creation. New York: Routledge, 2001.

Stacey, R. D. Complexity and Group Processes: A Radically Social Understanding of Individuals. New York: Brunner-Routledge, 2003.

Stanley, D. "Comparative Dynamics: Healthy Collectivities and the Pattern Which Connects." Complicity: An International Journal of Complexity and Education 3, no. 1 (2006): 73-82.

Stanley, D. "Creating Healthy Learning Organizations: A Complex Approach to a Crisis of Perception " In Approaches to Educational Leadership and Practice, Edited by W. Smale and K. Young. Calgary, Alberta, Canada: Detselig Enterprises, To Appear.

Stanley, D. "On the Importance of Connectivity in Healthy Learning Organizations: A Comparative Dynamics Perspective." Paper presented at the Proceedings of the 2005 Complexity Science and Educational Research Conference, Loranger, LA, November 20-22 2005.

Thompson, E. Mind in Life: Biology, Phenomenology, and the Sciences of Mind. Cambridge, MA: Harvard University Press, 2007.

van den Berg, J. H. The Psychology of the Sickebed. Buffalo, NY: Prometheus Books, 1967.

van Manen, M. "Modalities of Body Experience in Illness and Health." Qualitative Health Research: An International, Interdisciplinary Journal 8, no. 1 (1998): 7-24.

van Manen, M. Researching Lived Experience: Human Science for an Action Sensitive Pedagogy. Albany, NY: State University of New York Press, 1990.

Varela, F. J. Ethical Know-How: Action, Wisdom, and Cognition, Writing Science. Stanford, CA: Stanford University Press, 1999.

Varela, F. J. "The Specious Present: A Neurophenomenology of Time Consciousness." In Naturaliæing Phenomenology: Issues in Contemporary Phenomenology and Cognitive Science, Edited by J. Petitot, F. J. Varela, B. Pachoud and J.-M. Roy, 266-314. Standford, CA: Standford University Press, 1999.

Varela, F. J., and J. Shear. "First-Person Methodologies: What, Why, How?" In The View from Within: First-Person Approaches to the Study of Consciousness, Edited by F. J. Varela and J. Shear, 1-14. Bowling Green, OH: Imprint Academic, 2000.

Varela, F. J. The View from Within: First-Person Approaches to the Study of Consciousness. Exeter, England: Imprint Academic, 1999.

Varela, F. J., E. Thompson, and E. Rosch. The Embodied Mind: Cognitive Science and Human Experience. Cambridge, MA: The MIT Press, 1991.

\section{About the Author}

Darren Stanley is an Assistant Professor of Elementary Education (Mathematics) in the Faculty of Education at the University of Windsor in Windsor, Ontario. He received his doctorate from the University of Alberta, and his research interests include the study of complex phenomena as a paradigm for understanding and framing aspects of health and healthy learning organizations, including healthy schools. Additionally, he is interested in the circulation of lived phenomena with complexity frameworks. As a teacher educator in the faculty's pre-service education program, he is interested in the 
ways in which pre-service teachers enact complexified understandings of mathematics and pedagogy. (E-mail address: dstanley@uwindsor.ca) 